\title{
Total Phenols and Flavonoids Content, Antioxidant Capacity and Lipase Inhibition of Root and Leaf Horseradish (Armoracia rusticana) Extracts
}

\author{
Luana Calabrone',2, Marilena Larocca' ${ }^{1}$, Stefania Marzocco3 ${ }^{3}$, Giuseppe Martelli1, \\ Rocco Rossano $^{*}$ \\ ${ }^{1}$ Department of Sciences, University of Basilicata, Potenza, Italy \\ 2Doctoral School of "BioEcoSystems and BioTechnology", Potenza, Italy \\ ${ }^{3}$ Department of Pharmacy, University of Salerno, Fisciano, Italy \\ Email: ${ }^{\text {rocco.rossano@unibas.it }}$
}

Received 30 November 2014; revised 17 December 2014; accepted 25 December 2014

Copyright (C) 2015 by authors and Scientific Research Publishing Inc.

This work is licensed under the Creative Commons Attribution International License (CC BY).

http://creativecommons.org/licenses/by/4.0/

(c) (i) Open Access

\begin{abstract}
Horseradish (Armoracia rusticana Gaertn) is a perennial crop belonging to the Brassicaceae family, widely used as spice in food and as herbal ingredient in ethno-medicine. This study evaluated the phenolic compounds content, antioxidant capacity and anti-lipase activity of methanol, methanol/water $(70 / 30, v / v)$ and methanol/water $(50 / 50, v / v)$ extracts of horseradish roots and leaves. Among the extracts tested, both roots and leaves aqueous methanolic $(70 / 30, \mathrm{v} / \mathrm{v}$ and $50 / 50, v / v)$ extracts showed higher total phenol and flavonoid contents and antioxidant capacity than the corresponding methanol extracts. But extraction yield was high for methanol/ water $(50 / 50, v / v)$ extracts, in both roots and leaves. The extracts exhibited anti-lipase activity in dose-dependent manner. The results showed that the extraction yield and the antioxidant capacity were strictly dependent on the solvent polarity. The results suggest that $A$. rusticana could provide opportunities for the development of functional food and further in vivo studies for obesity treatment.
\end{abstract}

\section{Keywords}

Anti-Lipase Activity, Antioxidant, Leaves, Horseradish, Roots

\footnotetext{
"Corresponding author.
}

How to cite this paper: Calabrone, L., Larocca, M., Marzocco, S., Martelli, G. and Rossano, R. (2015) Total Phenols and Flavonoids Content, Antioxidant Capacity and Lipase Inhibition of Root and Leaf Horseradish (Armoracia rusticana) Extracts. Food and Nutrition Sciences, 6, 64-74. http://dx.doi.org/10.4236/fns.2015.61008 


\section{Introduction}

Horseradish (Armoracia rusticana Gaertn) is a perennial crop belonging to the Brassicaceae family. Due to its extremely pungent root, horseradish is used fresh grated as condiment for meat and fish products or into sauces. Moreover, the ethno-medical uses of Armoracia rusticana leaves and roots have a long history [1]. Horseradish is rich in glucosinolates (GLSs) that provide the characteristic flavour [2] and aroma as a result of their breakdown into isothiocyanates (ITCs) and others sulfur compounds. Horseradish, as well as the other members of Brassicaceae family, represents a rich source of health-promoting phytochemicals, and their beneficial effects have been principally attributed to the anticancer properties of GLSs and their ITCs derivatives [3] [4] and vitamins [5]. Also, horseradish contains the complex mixture of phenolic compounds possessing antioxidant activity [6] [7]. It is well known that many phenolics as flavones, tannins and chalcones show the inhibitor effect against pancreatic lipase [8]-[11]. Up to now, no reports describing the anti-lipase activity of horseradish have been reported. Lipids are an important component in human diet; however, hyperlipidaemia resulting from their increased intake is directly associated with obesity and other diseases like diabetes, hypertension and cardiovascular pathologies [12]. The triglyceride absorption efficiency is one of the main factors contributing to the plasma triglyceride levels; however, the dietary triglycerides are not absorbed as such until hydrolyzed to free fatty acids by triacylglycerol lipases [13]. Pancreatic lipase represents a principal enzyme involved in the enterocytes triglyceride absorption. Thus, the inhibition of this digestive lipase represents an important strategy in the treatment of obesity [14]-[17]. To this end, several plants have been screened for their anti-lipase activity [18] [19]. It was observed that the extracts from plants belonging to different families as Brassicaceae (Brassica nigra and Raphanus sativus), Ericaceae (Arctostaphylos uva-ursi and Vaccinium myrtillus), Fabaceae (Pisum sativum and Phaseolus vulgaris), Solanaceae (Solanum tuberosum) and Rosaceae (Malus domestica, Filipendula ulmaria, Rubus ideaus) showed lipase inhibitory activity ranging from $40 \%$ to more than $70 \%$ [18].

In this paper we report the total phenol and flavonoid contents, antioxidant capacity and lipase inhibition of roots and leaves horseradish extracts obtained using three different solvents.

\section{Material and Methods}

\subsection{Chemicals}

All reagents used were of the highest grade and were purchased from Sigma-Aldrich (St. Louis, MO, USA), Carlo Erba (Milan, Italy), Bio-Rad Laboratories (Segrate, Italy) and GE Healthcare (Uppsala, Sweden).

\subsection{Plant Material}

Four horseradish (Armoracia rusticana Gaertn, Mey, and Scherb) samples named as: Acc1, Acc2, Acc3, Acc4 were harvested from a fields grown in Southern Italy (Accettur latitude $40^{\circ} 29^{\prime} \mathrm{N}$, longitude $16^{\circ} 9^{\prime} \mathrm{E}-\mathrm{Basilicata}$, Italy). For each sample, leaves (30 - $35 \mathrm{~cm}$ long) were caught, successively frozen in liquid nitrogen, lyophilized and then stored at $-70^{\circ} \mathrm{C}$. The corresponding roots (35- $40 \mathrm{~cm}$ long and $2.5-3.0 \mathrm{~cm}$ in diameter) were collected from the middle of the plants. Samples were cleaned with distilled water, dried with paper towels and quickly frozen in liquid nitrogen. Successively they were lyophilized, grinded into a fine powder and stored at $-70^{\circ} \mathrm{C}$.

\subsection{Preparation of Extracts}

For each sample ten grams of both leaf and root powders were extracted for $12 \mathrm{~h}$ at $30^{\circ} \mathrm{C}$ in a conical flask at $150 \mathrm{rpm}$ with $100 \mathrm{~mL}$ of three different solvents: methanol, methanol/water (70/30, v/v) and methanol/water $(50 / 50, \mathrm{v} / \mathrm{v})$. The extracts were recovered after centrifugation $\left(18,000 \times \mathrm{g}\right.$ for $4 \mathrm{~min}$ at $\left.20^{\circ} \mathrm{C}\right)$, filtered through filter paper and stored at $4^{\circ} \mathrm{C}$. To calculate the percent yields (w/w), an aliquot of each extract was evaporated in a rotary vacuum evaporator and weighed.

Yield of extract $(\%)=$ weight of extract/weight of sample $\times 100$.

\subsection{Total Phenolic Content}

Total phenolic content (TPC) of the root and leaf extracts was determined spectrophotometrically by FolinCiocalteu reagent [20] with some modifications. $2.5 \mathrm{~mL}$ of Folin-Ciocalteu reagent (diluted 10 times with water) 
was added to $0.5 \mathrm{~mL}$ of root or leaf extract and, after 3 minutes, $2 \mathrm{~mL}$ of $7.5 \%$ sodium carbonate was added. Then, after $2 \mathrm{~h}$ of incubation at room temperature (in the dark) the absorbance was measured at $765 \mathrm{~nm}$ using Ultrospec 2000 spectrophotomer (Pharmacia Biotech, Uppsala, Sweden). Total phenols content was determined as gallic acid equivalents (GAE) and expressed in terms of mg GAE/g dry mass of sample.

\subsection{Total Flavonoid Content}

Total flavonoids content (TFC) was determined by aluminium chloride method using quercetin as reference compound [21]. Briefly, $0.3 \mathrm{~mL}$ of each extract was mixed with $0.9 \mathrm{~mL}$ of methanol, $0.06 \mathrm{~mL}$ of $10 \%$ aluminum chloride, $0.06 \mathrm{~mL}$ of $1 \mathrm{M}$ potassium acetate and $1.7 \mathrm{~mL}$ of distilled water. The reaction mixtures were incubated at room temperature and after $30 \mathrm{~min}$ the absorbance was measured at $415 \mathrm{~nm}$. Total flavonoid content was determined as quercetin equivalent (QE) and expressed in terms of mg QE/g dry mass of sample.

\subsection{DPPH Radical Scavenging Activity}

Antioxidant capacity of the horseradish extracts was measured on the basis of free radical scavenging activities of the stable 2,2-diphenyl-1-picrylhydraziyl ( $\mathrm{DPPH}^{*}$ ) [22]. Briefly, $0.5 \mathrm{~mL}$ of the different concentrations of plant extracts (range $25-200 \mu \mathrm{g} / \mathrm{mL}$ ) were mixed with $2.5 \mathrm{~mL}$ of freshly prepared $\mathrm{DPPH}^{*}$ methanol solution (0004 $\mathrm{g} \mathrm{DPPH}^{*}$ to $100 \mathrm{~mL}$ methanol). After $30 \mathrm{~min}$ of incubation in the dark at room temperature, the absorbance was measured at $517 \mathrm{~nm}$. Radical scavenging activity of the samples was calculated as follows and expressed in terms of $\mathrm{IC}_{50}$, were $\mathrm{IC}_{50}$ values denote the concentration $(\mu \mathrm{g} / \mathrm{mL})$ of sample, which is required to scavenge $50 \%$ of DPPH free radicals. Gallic acid was used as standard.

DPPH radical scavenging activity $(\%)=(1-$ absorbance sample/absorbance of control $) \times 100$.

\subsection{Total Reducing Power}

Total reducing power (TRP) of the extracts was determined according to Oyaizu [23] with some modification. Different concentration of root and leaf extracts $(25-200 \mu \mathrm{g} / \mathrm{mL}$ ), were mixed with $2.5 \mathrm{~mL}$ of $0.2 \mathrm{M}$ sodium phosphate buffer $\mathrm{pH} 6.6$ and $2.5 \mathrm{~mL}$ of $1 \%$ potassium ferricyanide. After $30 \mathrm{~min}$ of incubation at $50^{\circ} \mathrm{C}, 2.5 \mathrm{~mL}$ of $10 \%$ trichloroacetic acid was added to the mixture and then centrifuged (10 $\mathrm{min}$ at $4000 \mathrm{~g}$ ). Afterwords, 2.5 $\mathrm{mL}$ of the supernatant was mixed with $2.5 \mathrm{~mL}$ of distilled water and $0.5 \mathrm{~mL}$ of $0.1 \%$ ferric chloride. The absorbance was read at $700 \mathrm{~nm}$ and was compared with the standard gallic acid.

\subsection{Assay for Pancreatic Lipase Inhibitory Activity}

For determining lipase inhibitory activity, the extracts were obtained by removal of the solvents in vacuo and dissolved in $100 \mathrm{mM}$ sodium phosphate buffer, $150 \mathrm{mM} \mathrm{NaCl}, \mathrm{pH} 7.0$. A solution containing $100 \mathrm{units} / \mathrm{mL}$ of porcine pancreatic lipase (Type II, Sigma, St. Louis, MO) was prepared in $100 \mathrm{mM}$ sodium phosphate buffer, $150 \mathrm{mM} \mathrm{NaCl}, \mathrm{pH}$ 7.0. Then a $10 \mathrm{mM}$ solution of $p$-nitrophenyl butyrate ( $p$-NPB) (Sigma) in acetonitrile was prepared. For each extract, aliquots of $25 \mu \mathrm{L}$ at different concentrations were pre-incubated with $25 \mu \mathrm{L}$ of enzyme solution for $15 \mathrm{~min}$ at $37^{\circ} \mathrm{C}$ then $50 \mu \mathrm{L}$ of substrate solution and $900 \mu \mathrm{L} 100 \mathrm{mM}$ sodium phosphate buffer, $150 \mathrm{mM} \mathrm{NaCl}$, pH 7.0 were added. The enzymatic reaction was allowed to proceed for $30 \mathrm{~min}$ at $37^{\circ} \mathrm{C}$. Inhibition of lipase activity was expressed as the percentage decrease in absorbance at $400 \mathrm{~nm}$ when lipase was incubated with the horseradish extracts. Lipase inhibition (\%) was calculated according the following formula:

$$
\operatorname{Inhibition}(\%)=[(\mathrm{A}-\mathrm{a})-(\mathrm{B}-\mathrm{b})] /(\mathrm{A}-\mathrm{a}) \times 100
$$

where A is the activity without inhibitor, a is the negative control without inhibitor, B is the activity with inhibitor, and $\mathrm{b}$ is the negative control with inhibitor.

\subsection{Statistical}

Data, corresponding to the mean of two independent extractions performed in triplicate $(n=6)$, were analyzed by one way analysis of variance (ANOVA) and significant differences at $P<0.05$ between the samples were determined by the Tukey's test. 


\section{Results and Discussion}

\subsection{Extraction Yield, Total Polyphenol and Flavonoid Contents}

The extraction yield, determined in the extracts of horseradish roots and leaves, obtained by using different extraction solvents, is shown in Table 1. No significant differences were found between the four samples tested. The root extracts showed a yield (range: $18.51 \%$ - 26.15\%) higher than the corresponding leaves extracts (range: $15.44 \%-21.31 \%)(P<0.05)$. For both roots and leaves, higher extraction yields were achieved with methanol/water $(50 / 50, \mathrm{v} / \mathrm{v})$ compared to methanol and methanol/water $(70 / 30, \mathrm{v} / \mathrm{v})(P<0.05)$. The mean yields of methanol, methanol/water $(70 / 30, \mathrm{v} / \mathrm{v})$ and methanol/water $(50 / 50, \mathrm{v} / \mathrm{v})$ of the roots extracts of $A$. rusticana were $19.24 \% \pm 0.74 \%, 20.06 \% \pm 1.12 \%$ and $25.40 \% \pm 0.13 \%$, respectively, whereas, for leaf extracts the mean yields were $16.12 \% \pm 0.54 \%, 16.86 \% \pm 0.29 \%$ and $20.68 \% \pm 0.55 \%$, respectively. Our results showed that, the increase of polarity solvent leads to a greater extraction yield, probably due to the major solubility of carbohydrates and proteins, as reported by several authors [24] [25]. The differences in the extract yields within roots and leaves might be ascribed to the different availability of extractable components, resulting from the varied chemical matrix composition. Phenolic compounds represent an important group of phytochemicals ubiquitously present in the plant kingdom, and they have received much attention due to their potential health benefits as antioxidant and protective agents against cancer and other several diseases. These compounds were largely studied in Brassica vegetables [26]-[28]. Total phenolic contents (TPC) of horseradish roots and leaves, as determined by Folin-Ciocalteu method, were reported as gallic acid equivalents/g dry mass (Figure 1). In all samples analyzed, the extracts obtained from leaves (Figure 1(b)) showed a TPC content (range: 3.85 - $2.56 \mathrm{mg}$ GAE/g dry mass) higher than the corresponding root extracts (Figure 1(a)) (range: 2.89 - $1.74 \mathrm{mg}$ GAE/g dry mass). Among the extracts, both roots and leaves aqueous methanolic (70/30, v/v and 50/50, v/v) extracts resulted to contained increased amount of phenolic compounds respect to the corresponding methanolic extracts $(P<0.05)$. The mean TPC of methanol, methanol/water (70/30, v/v) and methanol/water (50/50, v/v) of the roots extracts were $1.80 \pm 0.17,2.36 \pm 0.14$ and $2.61 \pm 0.20$, respectively, whereas, for leaf extracts the mean TPC were $2.72 \pm$ $0.21,3.55 \pm 0.26$ and $3.35 \pm 0.20$, respectively. No significant differences were found between the four samples tested. Results of the present study showed that aqueous methanol extracts of roots and leaves exhibited the highest phenolic contents. This might be due to the fact that phenolics are extracted in higher amounts in more polar solvents such as aqueous methanol or ethanol solutions as compared with absolute methanol or ethanol [29] [30]. The determined amounts of total phenolics from the four horseradish samples investigated in the present study were similar to what reported by Tomsone et al. [31] in their studies concerning the comparison of different solvent and extraction methods to isolate phenolic compounds from horseradish roots. Flavonoids are the

Table 1. Yield of root and leaf extracts using different solvent.

\begin{tabular}{|c|c|c|c|}
\hline \multirow{2}{*}{ Sample } & \multicolumn{3}{|c|}{ Yield \% } \\
\hline & $\mathrm{ME}$ & MW (70/30, v/v) & MW (50/50, v/v) \\
\hline \multirow{2}{*}{ Acc1 } & Roots $19.24^{* a} \pm 0.54$ & $20.16^{* a} \pm 0.61$ & $25.42^{* \mathrm{~b}} \pm 0.98$ \\
\hline & Leaves $16.73^{\mathrm{a}} \pm 0.88$ & $16.99^{\mathrm{a}} \pm 0.16$ & $20.33^{b} \pm 0.55$ \\
\hline \multirow{2}{*}{ Acc2 } & Roots $18.51^{* \mathrm{a}} \pm 0.81$ & $19.15^{* a} \pm 0.44$ & $25.94^{* \mathrm{~b}} \pm 1.17$ \\
\hline & Leaves $16.03^{\mathrm{a}} \pm 1.08$ & $16.43^{\mathrm{a}} \pm 0.56$ & $20.95^{\mathrm{b}} \pm 0.74$ \\
\hline \multirow{2}{*}{ Acc3 } & Roots $20.26^{* a} \pm 1.03$ & $21.61^{* a} \pm 1.54$ & $26.15^{* \mathrm{~b}} \pm 1.22$ \\
\hline & Leaves $16.26^{\mathrm{a}} \pm 1.11$ & $17.08^{\mathrm{a}} \pm 1.13$ & $21.31^{\mathrm{b}} \pm 1.12$ \\
\hline \multirow{2}{*}{ Acc4 } & Roots $18.96^{* a} \pm 0.77$ & $19.33^{* a} \pm 1.12$ & $24.09^{* \mathrm{~b}} \pm 0.77$ \\
\hline & Leaves $15.44^{\mathrm{a}} \pm 0.82$ & $16.95^{\mathrm{a}} \pm 0.95$ & $20.13^{\mathrm{b}} \pm 0.57$ \\
\hline \multirow{2}{*}{ Mean } & Roots $19.24^{* a} \pm 0.74$ & $20.26^{* a} \pm 1.12$ & $25.40^{* \mathrm{~b}} \pm 0.13$ \\
\hline & Leaves $16.12^{\mathrm{a}} \pm 0.54$ & $16.95^{\mathrm{a}} \pm 0.29$ & $20.68^{\mathrm{b}} \pm 0.55$ \\
\hline
\end{tabular}

Values are reported as mean \pm SD of two independent experiments performed in Triplicate $(n=6)$. The mean values with different letters superscript in the same row are significantly different $(P<0.05$, Tukey's test) as analyzed by one-way analysis of variance ANOVA. The mean values with asterisk subscript within the same column indicate significant $(P<0.05)$ differences of means within the roots and leaves. ME, methanol; MW, methanol/water. 


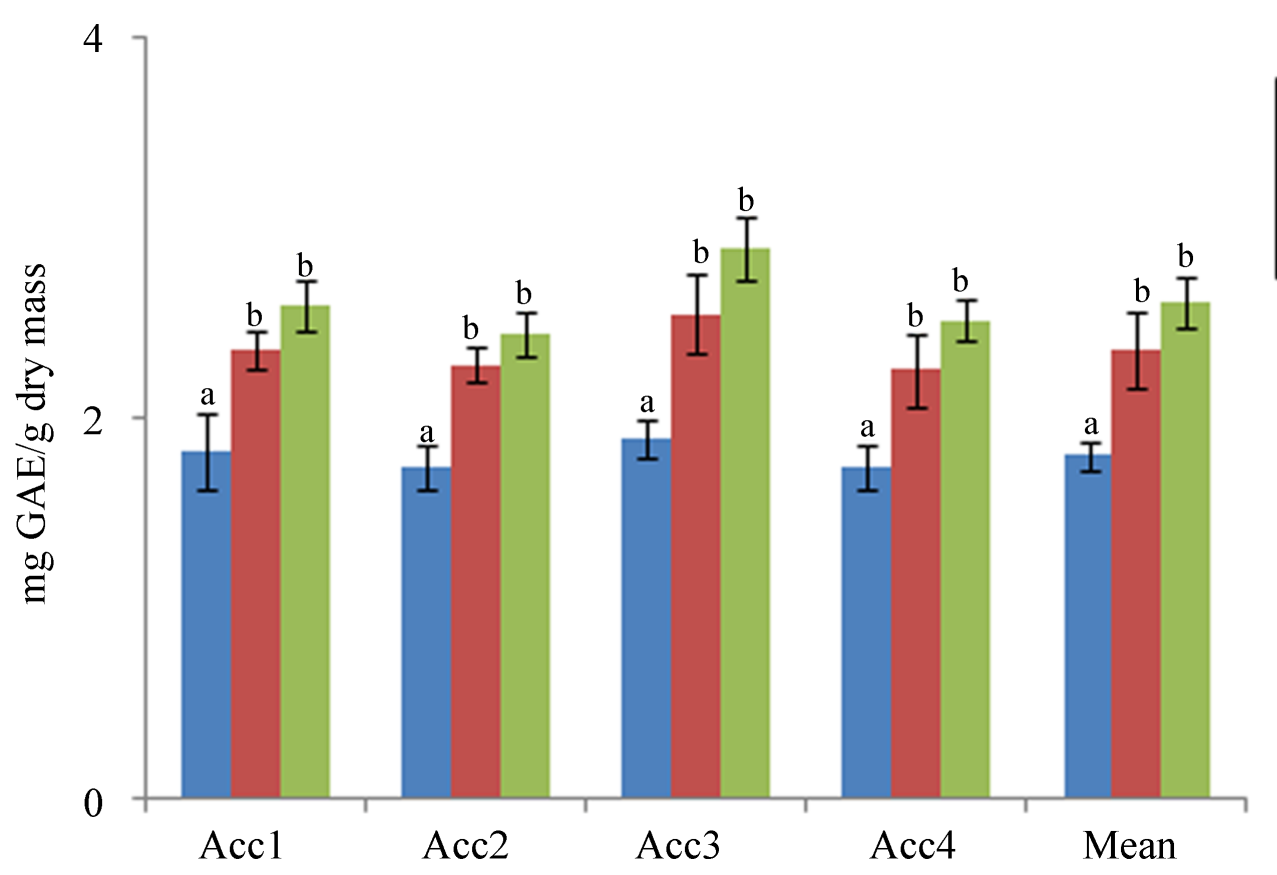

(a)

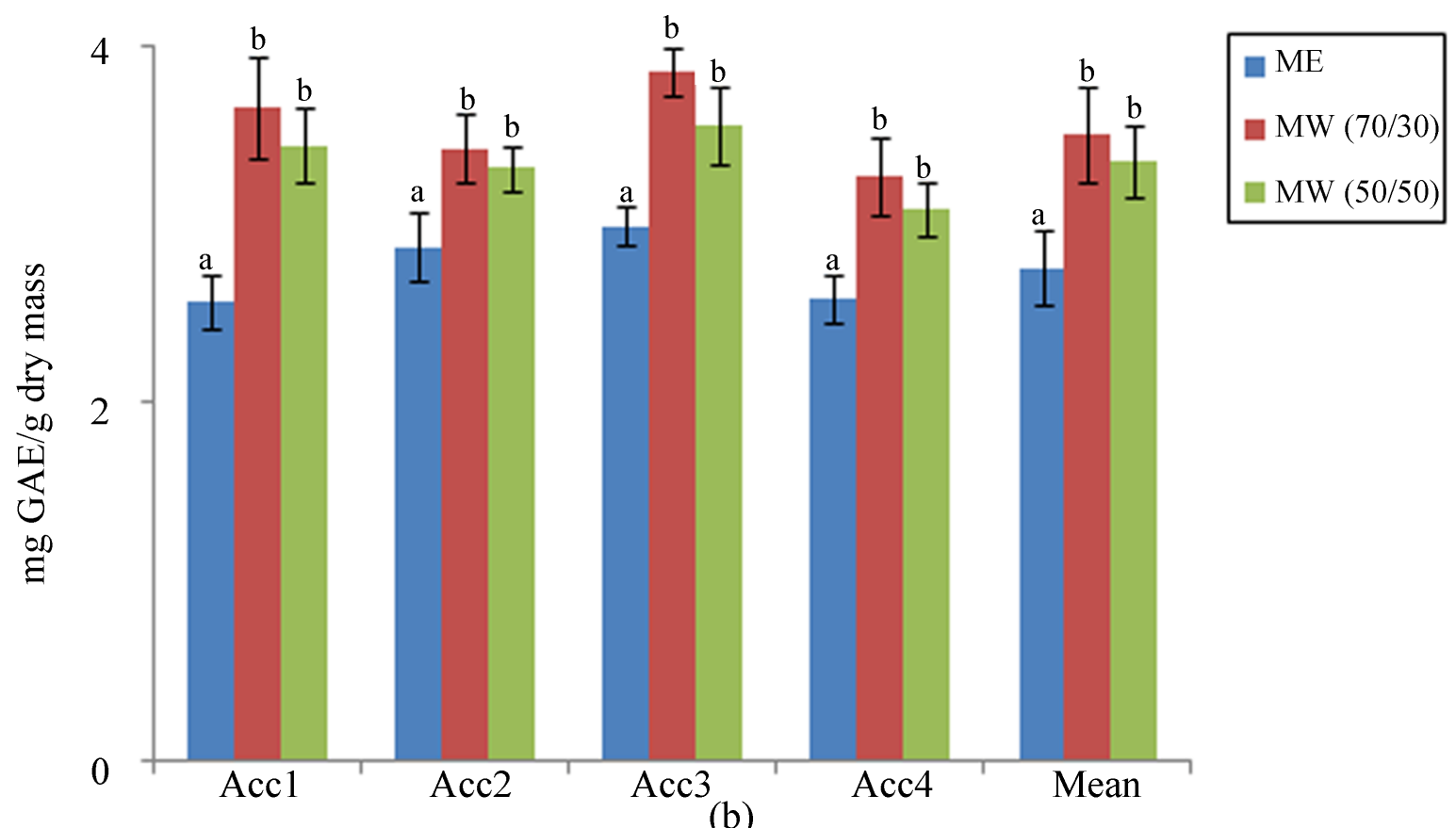

Figure 1. Total phenols content of horseradish extracts. Total phenols content of roots (a) and leaves extracts (b) was determined using Folin-Ciocalteu reagent and expressed as mg of gallic acid equivalents (GAE)/g dry mass of sample.

most abundant polyphenols in plants. Due to their hydroxyl groups, flavonoids show antioxidant activity and have radical scavenging effect in the plants [32] [33], also providing health beneficial effects [34]. Total flavonoid contents (TFC) of horseradish roots and leaves, as determined by the aluminum chloride method were reported as quercetin equivalents/g dry mass (Figure 2). The content of flavonoids in the samples followed the same trend as polyphenols. Leaves extracts (Figure 2(b)) showed a TFC (range: 1.71 - 0.95 mg QE/g dry mass) higher than the corresponding roots extracts (Figure 2(a)) (range: 1.26 - $0.75 \mathrm{mg} \mathrm{GAE} / \mathrm{g}$ dry mass). Amount of 


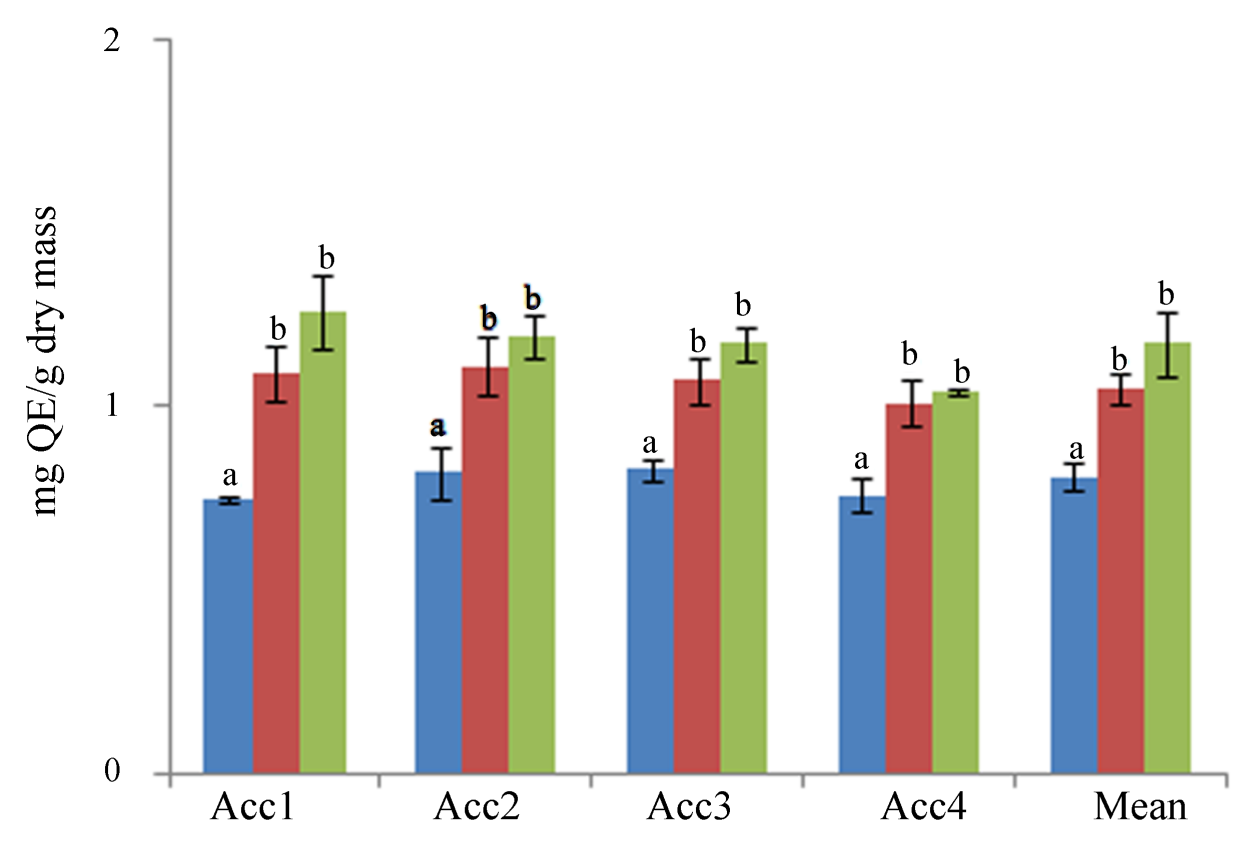

(a)

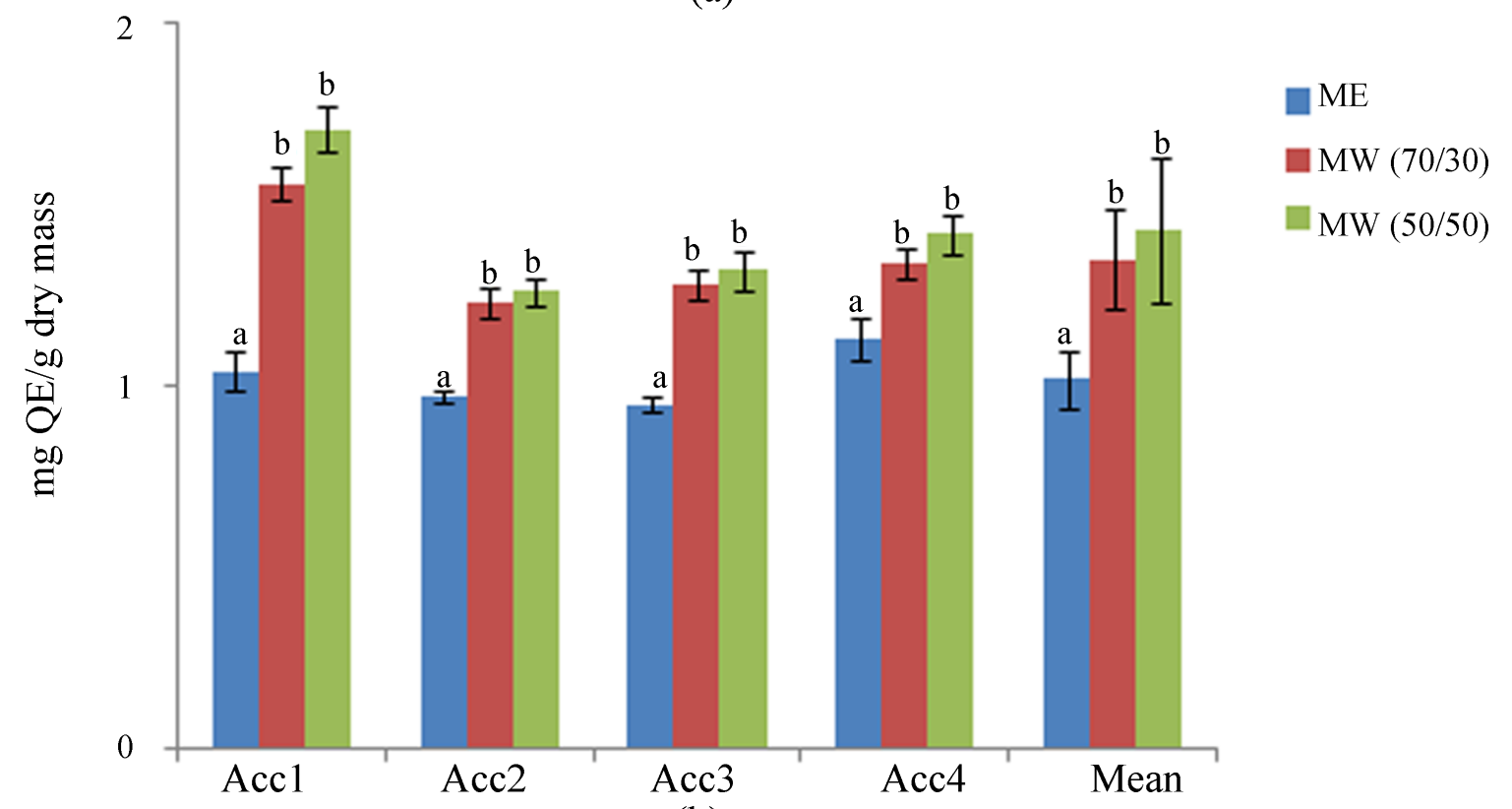

(b)

Figure 2. Total flavonoids content of horseradish extracts. Total flavonoids content of roots (a) and leaves extracts (b) was determined by aluminium chloride method and expressed as mg of quercetin equivalent (QE)/g dry mass of sample.

TFC in all the aqueous methanol $(70 / 30, \mathrm{v} / \mathrm{v}$ and 50/50, v/v) extracts were significantly higher $(P<0.05)$ than that one obtained using methanol. Results showed that flavonoids represent about $45 \%$ and $40 \%$ of the total phenolic compounds in roots and leaves, respectively.

\subsection{DPPH Radical Scavenging Activity}

The DPPH radical has been commonly used to evaluate the free radical scavenging activities of compounds. In this contest, lower $\mathrm{IC}_{50}$ value reflected higher antioxidant activity. The radical scavenging activity of extracts obtained from roots and leaves of the four horseradish samples, was tested by DPPH method and the results are 
showed in Table 2. No significant differences were found among the four samples analyzed. The aqueous methanol $(70 / 30, \mathrm{v} / \mathrm{v}$ and $50 / 50, \mathrm{v} / \mathrm{v})$ extracts from roots and leaves were found to be more $(P<0.05)$ active radical scavengers than the corresponding methanolic extracts. In roots, meanly $\mathrm{IC}_{50}$ values were $65.15 \pm 3.52,50.94 \pm$ 3.08 and $48.82 \pm 2.34 \mu \mathrm{g} / \mathrm{mL}$, for methanol, methanol/water (70/30, v/v) and methanol/water (50/50, v/v), respectively, whereas in leaves, $76.40 \pm 1.91,63.83 \pm 1.40$ and $63.1 \pm 2.36 \mu \mathrm{g} / \mathrm{mL}$, for methanol, methanol/water $(70 / 30, \mathrm{v} / \mathrm{v})$ and methanol/water (50/50, v/v), respectively. IC 50 value of gallic acid was $3.86 \pm 0.21 \mu \mathrm{g} / \mathrm{mL}$. It has well established that free radical scavenging activity of plant extracts is mainly due to phenolic compounds. The aqueous methanol $(70 / 30, \mathrm{v} / \mathrm{v}$ and 50/50, $\mathrm{v} / \mathrm{v})$ roots and leaves extracts containing the highest amounts of the total polyphenols, were found to be more $(P<0.05)$ active radical scavengers than the corresponding methanolic extracts. Contrarily to total phenolic contents, the extracts from the roots showed higher DPPH scavenging activity comparing to those extracts from the leaves. This different trend within the scavenging activity and polyphenol content might be attributed to the major presence in roots extracts of non-phenolic antioxidant compounds that do not react using the conventional Folin method [35]. Some researcher [7] has reported that oil obtained from horseradish roots showed a high antioxidant activity compared to synthetic antioxidant such as butylated hydroxyanisole (BHA) and butylated hydroxytoluene (BHT), or natural antioxidant such as $\alpha$-tocopherol, whereas Majewska and co-workers [6] report the weak antioxidant properties of leaf and root water-extracts originated from four different types of horseradish cultivated in Poland.

\subsection{Determination of Reducing Power}

It has well established that the reducing capacity of bioactive compounds is related to the antioxidant activity. The reducing power of extracts obtained from roots and leaves of the four horseradish samples, expressed as 1 $\mu g$ gallic acid equivalent, is showed in Table 3 . Lower concentration values reflected higher reducing capacity. The reducing power in the samples followed the same trend as radical scavenging activity. The extracts obtained from roots showed an activity (range: $96.79 \pm 5.49-118.56 \pm 3.18 \mu \mathrm{g} / \mathrm{mL}$ ) higher than the corresponding leaves extracts (range: $106.11 \pm 9.06-130.31 \pm 3.92 \mu \mathrm{g} / \mathrm{mL})(P<0.05)$. For both roots and leaves, higher activity were achieved with aqueous methanol $(70 / 30, \mathrm{v} / \mathrm{v}$ and $50 / 50, \mathrm{v} / \mathrm{v})$ extracts than the corresponding methanol extracts $(P<0.05)$. In roots, meanly $\mathrm{IC}_{50}$ values were $113.70 \pm 3.51,100.34 \pm 1.51$ and $99.00 \pm 2.38 \mu \mathrm{g} / \mathrm{mL}$, for methanol, methanol/water (70/30, v/v) and methanol/water (50/50, v/v), respectively, whereas in leaves, $125.15 \pm 3.67$, $111.83 \pm 3.22$ and $108.01 \pm 2.18 \mu \mathrm{g} / \mathrm{mL}$, for methanol, methanol/water (70/30, $\mathrm{v} / \mathrm{v})$ and methanol/water (50/50, $\mathrm{v} / \mathrm{v})$, respectively. Results showed that, in the extracts, reducing potential of antioxidant components is strictly associated with their TPC, but such as for DPPH radical scavenging activity, we noticed the same reverse trend within the reducing power and polyphenol content between root and leaves extracts.

Table 2. DPPH radical scavenging activity of root and leaf extracts.

\begin{tabular}{cccc}
\hline \multirow{2}{*}{ Sample } & ME & DPPH $\left(\mathrm{IC}_{50} \mu \mathrm{g} / \mathrm{mL}\right)$ & MW $(50 / 50, \mathrm{v} / \mathrm{v})$ \\
\cline { 2 - 4 } & Roots $68.42^{* \mathrm{a}} \pm 2.89$ & $\mathrm{MW}(70 / 30, \mathrm{v} / \mathrm{v})$ & $51.22^{* \mathrm{~b}} \pm 3.77$ \\
Acc1 & Leaves $76.42^{\mathrm{a}} \pm 3.98$ & $53.73^{* \mathrm{~b}} \pm 4.12$ & $61.73^{\mathrm{b}} \pm 4.12$ \\
& Roots $65.94^{* \mathrm{a}} \pm 2.17$ & $62.22^{\mathrm{b}} \pm 3.77$ & $49.11^{* \mathrm{~b}} \pm 2.44$ \\
Acc2 & Leaves $74.94^{\mathrm{a}} \pm 4.34$ & $51.07^{* \mathrm{~b}} \pm 5.93$ & $61.07^{\mathrm{b}} \pm 8.93$ \\
& Roots $60.15^{* \mathrm{a}} \pm 4.32$ & $63.15^{\mathrm{b}} \pm 3.44$ & $45.61^{* \mathrm{~b}} \pm 4.54$ \\
Acc3 & Leaves $75.15^{\mathrm{a}} \pm 4.22$ & $46.62^{* \mathrm{~b}} \pm 5.91$ & $63.62^{\mathrm{b}} \pm 7.91$ \\
& Roots $66.09^{* \mathrm{a}} \pm 3.77$ & $64.61^{\mathrm{b}} \pm 4.54$ & $49.33^{* \mathrm{~b}} \pm 5.12$ \\
Acc4 & Leaves $79.09^{\mathrm{a}} \pm 4.77$ & $52.34^{* \mathrm{~b}} \pm 6.63$ & $66.34^{\mathrm{b}} \pm 3.63$ \\
& Roots $65.15^{* \mathrm{a}} \pm 3.52$ & $65.33^{\mathrm{b}} \pm 5.12$ & $48.82^{* \mathrm{~b}} \pm 2.34$ \\
Mean & Leaves $76.40^{\mathrm{a}} \pm 1.91$ & $50.94^{* \mathrm{~b}} \pm 3.08$ & $63.19^{\mathrm{b}} \pm 2.36$ \\
Gallic acid & $3.86 \pm 0.21$ & $63.83^{\mathrm{b}} \pm 1.40$ & $3.86 \pm 0.21$ \\
\hline
\end{tabular}

Values are reported as mean \pm SD of two independent experiments performed in Triplicate $(\mathrm{n}=6) .{ }^{\mathrm{a}}$ The mean values with different letters superscript in the same row are significantly different $(P<0.05$, Tukey's test) as analyzed by one-way analysis of variance ANOVA. The mean values with asterisk subscript within the same column indicate significant $(P<0.05)$ differences of means within the roots and leaves. DPPH: 2,2-diphenyl-1picrylhydraziyl; ME, methanol; MW, methanol/water. 

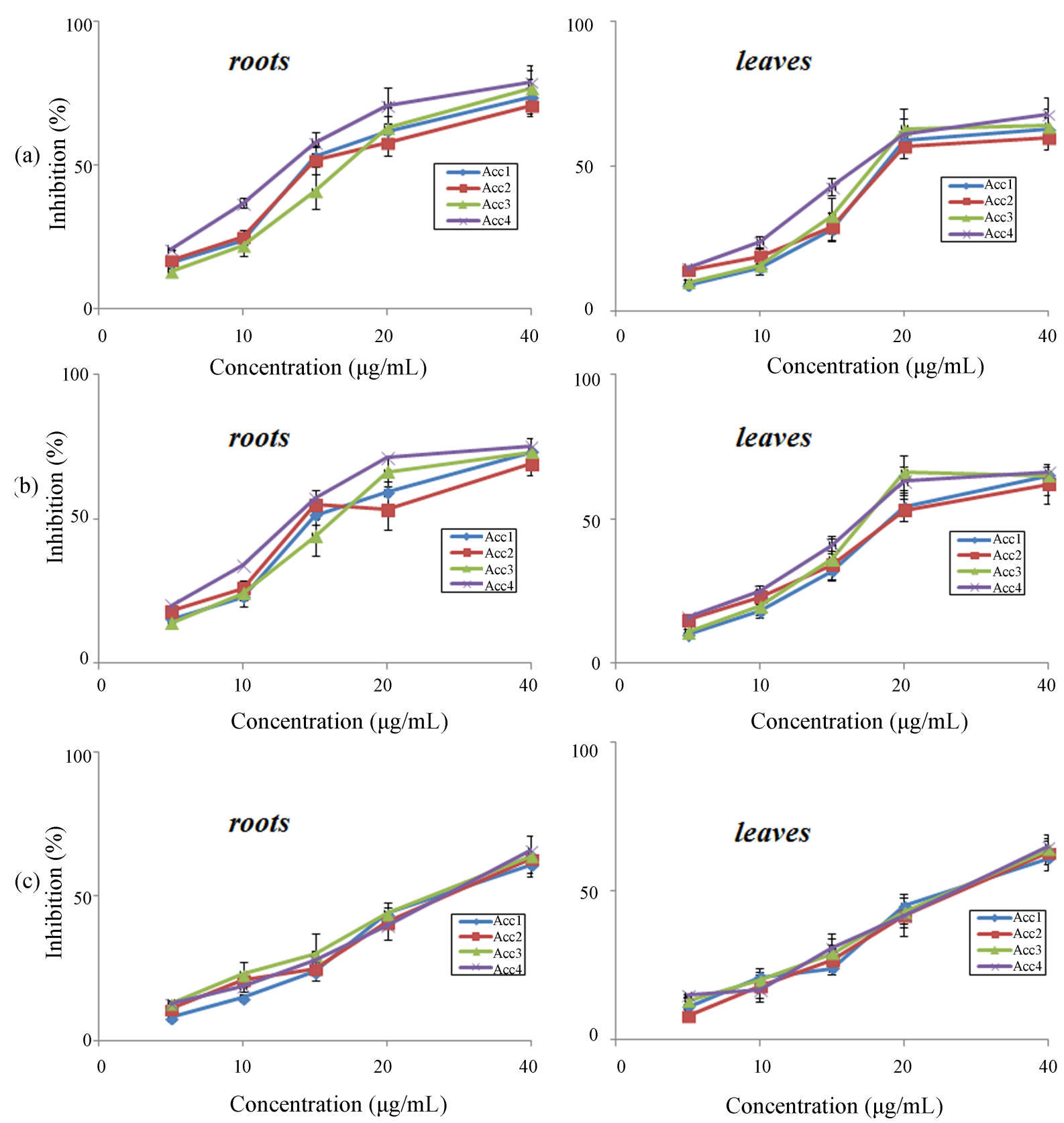

Figure 3. Lipase inhibition activity of horseradish extracts. Lipase inhibitory effect of roots and leaves extracts obtained by using methanol (a) and aqueous methanolic (70/30, v/v and 50/50, v/v) extracts ((b) and (c), respectively).

\subsection{Pancreatic Lipase Inhibitory Activity}

Recently, newer approaches for the treatment of obesity have involved inhibition of dietary triglyceride absorption via inhibition of pancreatic lipase [14]. In this study, we checked the pancreatic lipase inhibitory activities of horseradish roots and leaves extracts obtained by using three different solvents. The enzyme inhibition was expressed as $\mathrm{IC}_{50}$ value (the concentration required to inhibit a lipase activity by $50 \%$ ) (Figure 3 ). All the extracts exhibited inhibitory effect in dose-dependent manner with an $\mathrm{IC}_{50}$ value ranging from $15.96 \pm 0.82$ to $23.66 \pm 1.05 \mu \mathrm{g} / \mathrm{mL}$. No significant difference was found between the four samples tested. For both roots and leaves, methanolic and aqueous methanol (70/30, v/v) extracts (Figure 3(a) and Figure 3(b), respectively) showed higher activity $(P<0.05)$ than the corresponding aqueous methanol $(50 / 50, \mathrm{v} / \mathrm{v})$ extracts $($ Figure $3(\mathrm{c}))$. 
Table 3. Total reducing power of root and leaf extracts.

\begin{tabular}{|c|c|c|c|}
\hline \multirow{2}{*}{ Sample } & \multicolumn{3}{|c|}{ TRP ( $\mu$ g gallic acid equivalent) } \\
\hline & ME & MW (70/30, v/v) & MW (50/50, v/v) \\
\hline \multirow{2}{*}{ Acc1 } & Roots $112.03^{* \mathrm{a}} \pm 5.12$ & $99.42^{* \mathrm{~b}} \pm 3.21$ & $102.12^{\mathrm{b}} \pm 5.99$ \\
\hline & Leaves $124.71^{\mathrm{a}} \pm 3.06$ & $108.12^{\mathrm{b}} \pm 4.32$ & $106.24^{\mathrm{b}} \pm 5.77$ \\
\hline \multirow{2}{*}{ Acc2 } & Roots $113.76^{\mathrm{a}} \pm 3.53$ & $101.33^{* \mathrm{~b}} \pm 4.27$ & $97.54^{* \mathrm{~b}} \pm 4.16$ \\
\hline & Leaves $123.91^{* \mathrm{a}} \pm 4.41$ & $113.71^{\mathrm{b}} \pm 6.34$ & $110.48^{\mathrm{b}} \pm 3.75$ \\
\hline \multirow{2}{*}{ Acc3 } & Roots $110.44^{*_{a}} \pm 4.82$ & $98.71^{* \mathrm{~b}} \pm 5.39$ & $96.79^{* \mathrm{~b}} \pm 5.49$ \\
\hline & Leaves $121.67^{\mathrm{a}} \pm 3.83$ & $115.21^{\mathrm{b}} \pm 4.54$ & $109.21^{\mathrm{b}} \pm 6.79$ \\
\hline \multirow{2}{*}{ Acc 4} & Roots $118.56^{*_{a}} \pm 3.18$ & $101.88^{* b} \pm 4.52$ & $99.56^{\mathrm{b}} \pm 4.18$ \\
\hline & Leaves $130.31^{\mathrm{a}} \pm 3.92$ & $110.26^{\mathrm{b}} \pm 2.11$ & $106.11^{\mathrm{b}} \pm 9.06$ \\
\hline \multirow{2}{*}{ Mean } & Roots $113.70^{* a} \pm 3.51$ & $100.34^{* \mathrm{~b}} \pm 1.51$ & $99.00^{* b} \pm 2.38$ \\
\hline & Leaves $125.15^{\mathrm{a}} \pm 3.67$ & $111.83^{\mathrm{b}} \pm 3.22$ & $108.01^{\mathrm{b}} \pm 2.18$ \\
\hline
\end{tabular}

Values are reported as mean \pm SD of two independent experiments performed in Triplicate $(n=6) .{ }^{a}$ The mean values with different letters superscript in the same row are significantly different $(P<0.05$, Tukey's test) as analyzed by one-way analysis of variance ANOVA. The mean values with asterisk subscript within the same column indicate significant $(P<0.05)$ differences of means within the roots and leaves of same sample. TRP: total reducing power; ME, methanol; MW, methanol/water.

For all solvents, not significant differences $(P<0.05)$ were found between root and the corresponding leaf extracts. To our knowledge, there are no data on the presence of anti-lipase activity in A. rusticana plant. In a recent study, Slanc et al. [19] reports on the presence of lipase inhibitory activity in other four Brassicaceae plants (Brassica nigra, Raphanus sativus, Brassica oleracea capitata and Brassica oleracea var botrytis).

\section{Conclusion}

The results of the present investigation revealed that aqueous solvent extracts of plant materials, exhibited better antioxidant capacity and higher phenolic contents. The absence of differences on the phenolics content and antioxidant capacity among the four horseradish samples tested, might be ascribed to the fact that samples were caught in the same place. On the other hand, Majewska et al. [6] reported that the most important factor which had impact on the antioxidant compounds of horseradish was the place of plant cultivation. The results also suggest that A. rusticana would represent a potential source of drug for the treatment of obesity. However, further in vivo studies are needed to identify and characterize the inhibitory-lipase compounds and for the development of functional food for obesity treatment.

\section{Acknowledgements}

This study was supported by a grant from University of Basilicata (Ricerca Interesse Locale, 2011) and by a grant from Basilicata Region (Mis 214 Azione 5 Agrobiodiversità: "Biodiversità di specie orticole ed areali lucani:da patrimonio a strumento di sviluppo").

\section{References}

[1] Agneta, R., Mollers, C. and Rivelli, A.R. (2013) Horseradish (Armoracia rusticana), a Neglected Medical and Condiment Species with a Relevant Glucosinolate Profile: A Review. Genetic Resources and Crop Evolution, 60, 19231943. http://dx.doi.org/10.1007/s10722-013-0010-4

[2] Kushad, M.M., Brown, A.F., Kurilich, A.C., Juvik, J.A., Klein, P., Wallig, M.A. and Jeffery, E.H. (1999) Variation of Glucosinolates in Vegetable Crops of Brassica oleracea. Journal of Agricultural and Food Chemistry, 47, 1541-1548. http://dx.doi.org/10.1021/jf980985s

[3] Van Poppel, G., Verhoeven, D.T., Verhagen, H. and Goldbohm, R.A. (1999) Brassica Vegetables and Cancer Prevention. Epidemiology and Mechanism. Advances in Experimental Medicine and Biology, 472, 159-168.

http://dx.doi.org/10.1007/978-1-4757-3230-6_14 
[4] Zhang, L., Tan, Q., Lee, R., Trethewy, A., Lee, Y.H. and Tegeder, M. (2010) Altered Xylem-Phloem Transfer of Amino Acids Affects Metabolism and Leads to Increased Seed Yield and Oil Content in Arabidopsis. Plant Cell, 22, 3603-3620. http://dx.doi.org/10.1105/tpc.110.073833

[5] Mazza, G. (1984) Volatiles in Distillates of Fresh, Dehydrated and Freeze Dried Horseradish. Canadian Institute of Food Sciences and Technology Journal, 17, 18-23. http://dx.doi.org/10.1016/S0315-5463(84)72310-8

[6] Majewska, A., Bałasińska, B. and Dąbrowska, B. (2004) Antioxidant Properties of Leaf and Root Extract and Oil from Different Types of Horseradish (Armoracia rusticana Gaertn). Folia Horticolturae, 16, 15-22.

[7] Velioglu, Y.S., Mazza, G., Gao, L. and Oomah, B.D. (1998) Antioxidant Activity and Total Phenolics in Selected Fruits, Vegetables, and Grain Products. Journal of Agricultural and Food Chemistry, 46, 4113-4117. http://dx.doi.org/10.1021/jf9801973

[8] Kawaguchi, K., Mizuno, T., Aida, K., Uchino, K. (1997) Hesperidin as an Inhibitor of Lipases from Porcine Pancreas and Pseudomonas. Biosciences and Biotechnology Biochemistry, 61, 102-104. http://dx.doi.org/10.1271/bbb.61.102

[9] Moreno, D., Ripoll, C., Ilic, N., Poulev, A., Aubin, C. and Raskin, I. (2006) Inhibition of Lipid Metabolic Enzymes Using Mangifera indica Extracts. Journal of Food Agricultural Environmental, 4, 21-26.

[10] Nakai, M., Fukui, Y., Asami, S., Toyoda-Ono, Y., Iwashita, T., Shibata, H., Mitsunaga, T., Hashimoto, F. and Kiso, Y. (2005) Inhibitory Effects of Oolong Tea Polyphenols on Pancreatic Lipase in Vitro. Journal of Agricultural and Food Chemistry, 53, 4593-4598. http://dx.doi.org/10.1021/jf047814+

[11] Shin, J.E., Joo Han, M. and Kim, D.H. (2003) 3-Methylethergalangin Isolated from Alpinia officinarum Inhibits Pancreatic Lipase. Biological and Pharmaceutical Bulletin, 26, 854-857. http://dx.doi.org/10.1248/bpb.26.854

[12] Kopelman, P.G. (2000) Obesity as a Medical Problem. Nature, 404, 635-643.

[13] Verger, R. (1997) Interfacial Activation of Lipases: Facts and Antifacts. Trends in Biosciences, 15, 32-37.

[14] Birari, R.B. and Bhutani, K.K. (2007) Pancreatic Lipase Inhibitors from Natural Sources: Unexplored Potential. Drug Discovery Today, 12, 879-889. http://dx.doi.org/10.1016/j.drudis.2007.07.024

[15] Kim, Y.S., Lee, Y.M., Kim, H., Kim, J., Jang, D.S., Kim, J.H. and Kim, J.S. (2010) Anti-Obesity Effect of Morus bombycis Root Extract: Anti-Lipase Activity and Lipolytic Effect. Journal of Ethnopharmacology, 130, 621-624. http://dx.doi.org/10.1016/j.jep.2010.05.053

[16] Mancini, M.C. and Halpern, A. (2006) Investigational Therapies in the Treatment of Obesity. Expert Opinion on Investigational Drugs, 15, 897-915. http://dx.doi.org/10.1517/13543784.15.8.897

[17] Shi, Y. and Burn, P. (2004) Lipid Metabolic Enzymes: Emerging Drug Targets for the Treatment of Obesity. Nature Reviews Drug Discovery, 3, 695-710. http://dx.doi.org/10.1038/nrd1469

[18] Sharma, N., Sharma, V.K. and Seo, S.Y. (2005) Screening of Some Medicinal Plants for Anti-Lipase Activity. Journal of Ethnopharmacology, 97, 453-456. http://dx.doi.org/10.1016/j.jep.2004.11.009

[19] Slanc, P., Doljak, B., Kreft, S., Lunder, M., Janes, D. and Strukelj, B. (2009) Screening of Selected Food and Medicinal Plant Extracts for Pancreatic Lipase Inhibition. Phytotheraphy Research, 23, 874-877. http://dx.doi.org/10.1002/ptr.2718

[20] Singleton, V.L., Orthofer, R. and Lamuela-Raventos, R.M. (1999) Analysis of Total Phenols and Other Oxidation Substrates and Antioxidants by Means of Folin-Ciocalteu Reagent. Methods in Enzymology, 29, 152-178. http://dx.doi.org/10.1016/S0076-6879(99)99017-1

[21] Chang, C., Yang, M., Wen, H. and Chern, J. (2002) Estimation of Total Flavonoid Content in Propolis by Two Complementary Colorimetric Methods. Journal of Food Drug Analysis, 10, 178-182.

[22] Yu, L., Haley, S., Perret, J., Harris, M., Wilson, J. and Haley, S. (2003) Antioxidant Properties of Bran Extracts from Akron Wheat Grown at Different Locations. Journal of Agricultural and Food Chemistry, 51, 1566-1570. http://dx.doi.org/10.1021/jf020950z

[23] Oyaizu, M. (1986) Studies on the Products of Browning Reaction Prepared from Glucose Amine. Japanese Journal of Nutrition, 44, 307-315. http://dx.doi.org/10.5264/eiyogakuzashi.44.307

[24] Dai, J. and Mumper, R.J. (2010) Plant Phenolics: Extraction, Analysis and Their Antioxidant and Anticancer Properties. Molecules, 15, 7313-7352. http://dx.doi.org/10.3390/molecules15107313

[25] Zhou, K. and Yu, L. (2004) Effects of Extraction Solvent on Wheat Bran Antioxidant Activity Estimation. LWT-Food Science and Technology, 37, 717-721. http://dx.doi.org/10.1016/j.lwt.2004.02.008

[26] Plumb, G.W., Price, K.R., Rhodes, M.J.C. and Williamson, G. (1997) Antioxidant Properties of the Major Polyphenolic Compounds in Broccoli. Free Radical Research, 27, 429-435. http://dx.doi.org/10.3109/10715769709065782

[27] Podsedek, A. (2007) Natural Antioxidants and Antioxidant Capacity of Brassica Vegetables: A Review. LWT-Food Science and Technology, 40, 1-11. http://dx.doi.org/10.1016/j.lwt.2005.07.023 
[28] Cartea, M.E., Francisco, M., Soengas, P. and Velasco, P. (2011) Phenolic Compounds in Brassica Vegetables. Molecules, 16, 251-280. http://dx.doi.org/10.3390/molecules16010251

[29] Alothman, M., Rajeev, B. and Karim, A.A. (2009) Antioxidant Capacity and Phenolic Content of Selected Tropical Fruits from Malaysia, Extracted with Different Solvents. Food Chemistry, 115, 785-788. http://dx.doi.org/10.1016/j.foodchem.2008.12.005

[30] Naczk, M. and Shaidi, F. (2006) Phenolic in Cereals, Fruit and Vegetables: Occurrence, Extraction and Analysis. Journal of Pharmaceutical and Biomedical Analysis, 41, 1523-1542. http://dx.doi.org/10.1016/j.jpba.2006.04.002

[31] Tomsone, L., Kruma, Z. and Galoburda, R. (2012) Comparison of Different Solvents and Extraction Methods for Isolation of Phenolic Compounds from Horseradish Roots (Armoracia rusticana). World Academy Science Engineering Technology, 64, 903-908.

[32] Younes, M. (1981) Inhibitory Action of Some Flavonoids on Enhanced Spontaneous Lipid Peroxidation Following Glutathione Depletion. Planta Medica, 43, 240-245. http://dx.doi.org/10.1055/s-2007-971503

[33] Cook, N.C. and Samman, S. (1996) Flavonoids-Chemistry, Metabolism, Cardioprotective Effects, and Dietary Sources. The Journal of Nutritional Biochemistry, 7, 66-76.

[34] Boots, A.W., Haenen, G.R.M.M. and Bast, A. (2008) Health Effects of Quercetin: From Antioxidant to Nutraceutical. European Journal of Pharmacology, 585, 325-337. http://dx.doi.org/10.1016/j.ejphar.2008.03.008

[35] Berker, K.I., Olgun, F.A.O., Ozyurt, D., Demirata, B. and Apak, R. (2013) Modified Folin-Ciocalteu Antioxidant Capacity Assay for Measuring Lipophilic Antioxidants. Journal of Agricultural and Food Chemistry, 61, 4783-4791. http://dx.doi.org/10.1021/jf400249k 
Scientific Research Publishing (SCIRP) is one of the largest Open Access journal publishers. It is currently publishing more than 200 open access, online, peer-reviewed journals covering a wide range of academic disciplines. SCIRP serves the worldwide academic communities and contributes to the progress and application of science with its publication.

Other selected journals from SCIRP are listed as below. Submit your manuscript to us via either submit@scirp.org or Online Submission Portal.
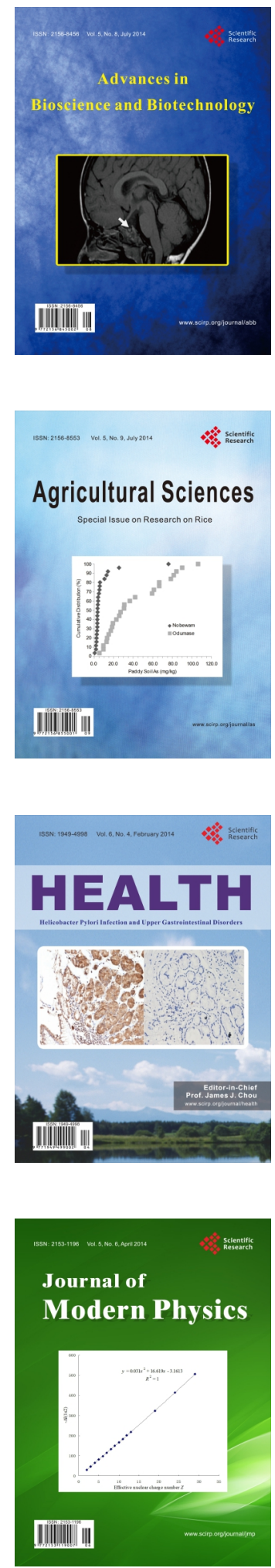
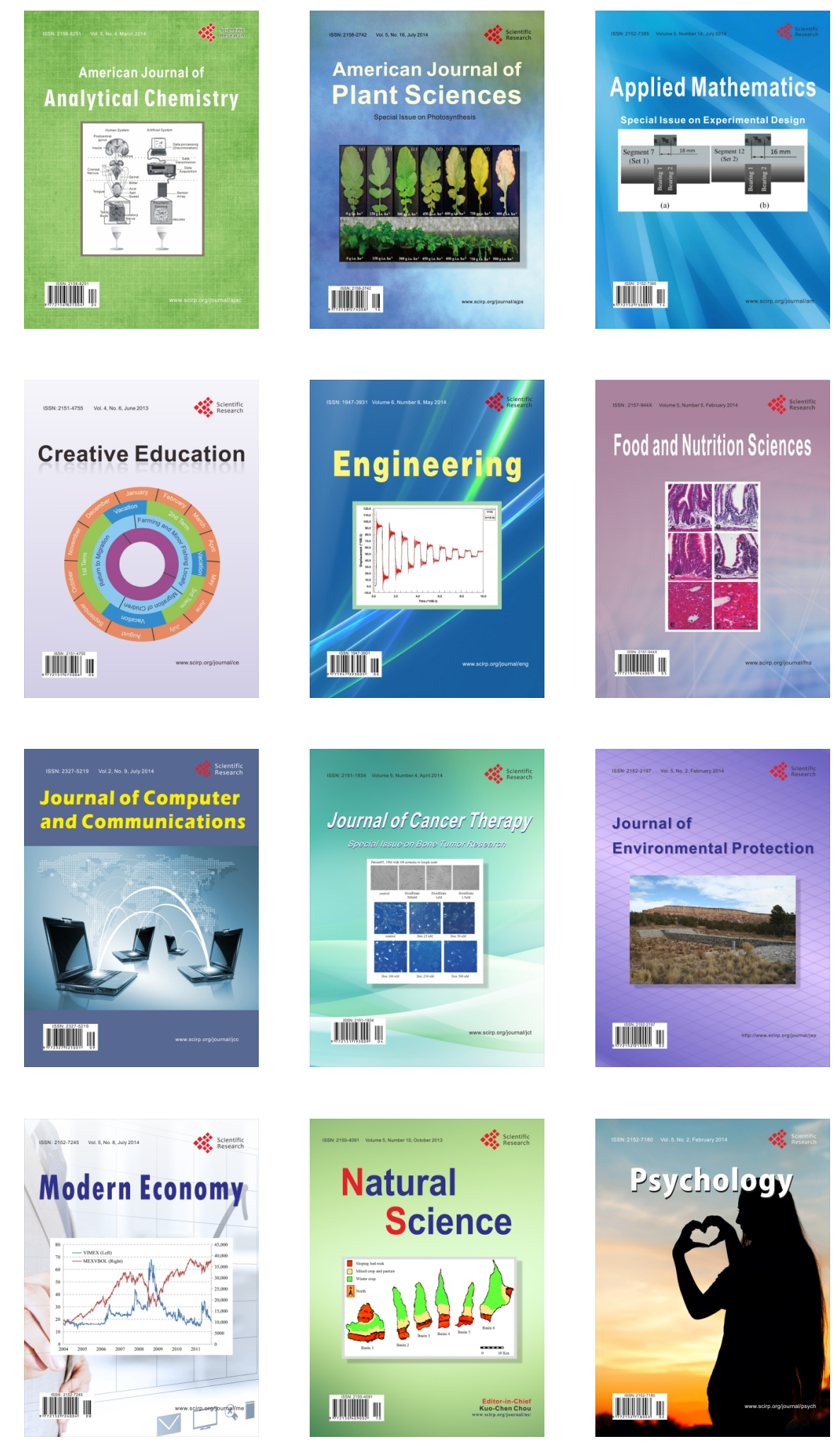